\title{
Comparison of the behaviour of manufactured and other airborne nanoparticles and the consequences for prioritising research and regulation activities
}

\author{
Prashant Kumar • Paul Fennell • Alan Robins
}

Received: 9 February 2010/Accepted: 1 March 2010/Published online: 17 March 2010

(C) Springer Science+Business Media B.V. 2010

\begin{abstract}
Currently, there are no air quality regulations in force in any part of the world to control number concentrations of airborne atmospheric nanoparticles (ANPs). This is partly due to a lack of reliable information on measurement methods, dispersion characteristics, modelling, health and other environmental impacts. Because of the special characteristics of manufactured (also termed engineered or synthesised) nanomaterials or nanoparticles (MNPs), a substantial increase is forecast for their manufacture and use, despite understanding of safe design and use, and health and environmental implications being in its early stage. This article discusses a number of underlining technical issues by comparing the properties and behaviour of MNPs with anthropogenically produced ANPs. Such a comparison is essential for the judicious treatment of the MNPs in any potential air quality regulatory framework for ANPs.
\end{abstract}

\section{P. Kumar $(\bowtie) \cdot$ A. Robins}

Faculty of Engineering and Physical Sciences,

Division of Civil, Chemical and Environmental

Engineering, Civil Engineering (C5),

University of Surrey, Guildford GU2 7XH, UK

e-mail: P.Kumar@surrey.ac.uk;

Prashant.Kumar@cantab.net

P. Fennell

Department of Chemical Engineering, Imperial College, London SW7 2AZ, UK
Keywords Dispersion - Engineered nanomaterials · Environmental impact · Manufactured nanoparticles · Particle number and size distributions . Nanoparticle regulations - Health and safety

\section{Introduction}

Recent scientific publications and internationally funded research make it abundantly clear that manufactured nanoparticles (MNPs) are attaining increasing attention from the air quality management and scientific communities, partly due to the forecast of substantially increased use in technological applications. Understanding of the properties of MNPs has improved in recent years (Nowack 2009) but there remain a number of unanswered questions related to their impacts on human health and the environment. The ultrafine fraction $(<100 \mathrm{~nm})$ of atmospheric nanoparticles (ANPs; here referring mainly to all anthropogenic aerosols or nanoparticles naturally in the ambient urban atmosphere) is already of great concern due to the small size and high surface area/ volume ratio of the particles that results in deep penetration into and greater deposition in human lungs (Anastasio and Martin 2001). Moreover, there are no air quality regulations in place in the UK, Europe or any other part of the world to control nanosized particle number concentrations, either in the atmosphere or indoors. 
First, it is important to note that we are using the term ANPs to refer to particles below $300 \mathrm{~nm}$ in size for several reasons: (i) this size range includes more than $99 \%$ of the total number concentrations of particles in ambient air (Kumar et al. 2008a, b, c, d, 2009a) (ii) the range includes the cut-off particle size range (i.e. 10 to $300 \mathrm{~nm}$ ) adopted in the Euro-5 and Euro-6 vehicle emission standards (EU 2008), and (iii) this includes the well-defined range of MNPs (i.e. 1-100 nm; BSI 2005). It should also be noted that the ANPs discussed here mainly refer to anthropogenically produced aerosol particles found in the ambient urban or polluted atmospheres where nearly all exposure to particle pollution occurs and is consequently the target for regulatory action. As a consequence of the Euro emission standards for vehicles, there will soon be ambient air quality standards in Europe for ANPs on a number basis. Therefore, this article discusses a number of technical aspects of MNPs and other ANPs on the basis of particle number concentrations. Understanding of these issues is essential for the judicious treatment of airborne MNPs while designing a potential regulatory framework for ANPs. Policy and governance issues are not included here but a detailed discussion on these can be found elsewhere (Franco et al. 2007; Satterstrom et al. 2009, and references therein).

Do the characteristics of MNPs differ from those of other ANPs?

Considering their origins, the answer of the above question could well be 'yes'. MNPs differ from other ANPs in many aspects: sources, composition, homogeneity or heterogeneity, size distribution, oxidant potential, toxicity, morphology, as well as potential pathways of exposure (Xia et al. 2009). Measurement methods, dispersion characteristics and life times in ambient air may also differ because of the inherent characteristics of MNPs. Concentrations in ambient air (away from areas associated with their production or use) are expected to be considerably smaller than those of other ANPs but may nevertheless have substantial impacts on human health and the environment (Ju-Nam and Lead 2008; Andujar et al. 2009). Characteristics of MNPs are compared with ANPs in the following sections and in summary in Table 1.
Should MNPs be regarded as an emerging class of ANPs?

The current impact of MNPs is not at all clear, given the dominance of natural (biomass burning, volcanic emissions and secondary formation, etc.) and anthropogenic (combustion of fossil fuels in power plants, vehicles, etc.) sources in urban environments, with road vehicles alone contributing as much as $86 \%$ of particle number concentrations in traffic-dominated areas (Pey et al. 2009). However, the matter can not be ignored because of the expected large increases in production and use of MNPs, and associated future investment in research. For example, Dawson (2008) writes that by 2014 more than $15 \%$ of all products globally will incorporate nanotechnology during their manufacture, with a value of about $\$ 1$ trillion per year by 2015 (Roco and Bainbridge 2001; Roco 2005). Another estimate has MNP production increasing from 2000 tons in 2004 to 58,000 tons by 2011-2020 (Maynard 2006). Moreover, considerable investments (e.g. nearly $\$ 40$ billion to the end of 2008 and $\$ 9.75$ billion in 2009 alone; Cientifica 2009) are currently being made globally by governments in nanotechnology research.

MNPs are not intentionally released into the ambient environment; their production takes place under controlled gas-phase conditions. However, fugitive emissions can arise at this stage and also during use and disposal of MNP-integrated products (Kuhlbusch et al. 2004; Fujitani et al. 2008; Brouwer 2009). Some products are inherently dispersive (sunscreens, food additives, etc.) while others are not (nano-plasticisers or stabilisers in concrete, nanosized silver particles in textile fabrics, etc.; The Royal Society 2004). In this context, it should be noted that several MNPs (carbon black, $\mathrm{ZiO}_{2}, \mathrm{TiO}_{2}$ and metal oxides, etc.) are produced as powders (Xia et al. 2009). A popular but potentially dangerous class of MNPs is carbon nanotubes (CNTs), which can enter the ambient environment by wear and tear of CNTintegrated products (e.g. batteries and textiles; Köhler et al. 2008) or within municipal solid waste (Bystrzejewska-Piotrowska et al. 2009). New and sometimes surprising sources continue to emerge; e.g. Evelyn et al. (2002) report results indicating that the combustion of diesel fuels in vehicles produced CNTtype structures, with an aspect ratio partly in the range seen for lung-retained asbestos, underlining 
Table 1 Comparison of selected properties of ANPs and MNPs (Oberdörster et al. 2005; Stone et al. 2009; Xia et al. 2009; Brouwer 2009; Kumar et al. 2008a, b, c, d; Kumar et al. 2009a, b)

\begin{tabular}{|c|c|c|}
\hline Characteristics & ANPs & MNPs \\
\hline Source & Combustion & Engineering (controlled synthesis) \\
\hline Most popular class & $\begin{array}{l}\text { Volatile organics, sulpur compounds } \\
\text { and carbonaceous agglomerates }\end{array}$ & Silver, $\mathrm{TiO}_{2}$ and $\mathrm{CNTs}$ \\
\hline Physicochemical properties & $\begin{array}{l}\text { Volatile or semi-volatile, scattering } \\
\text { and absorption }\end{array}$ & $\begin{array}{l}\text { Non-volatile, conductive, super-hard, optical absorption, } \\
\text { magnetism (properties of MNPs differ from those of their } \\
\text { bulk material) }\end{array}$ \\
\hline Organic chemical content & High & Low \\
\hline Metal impurities & Low & Varies \\
\hline Atmospheric release & Intentional or incidental (fugitive) & $\begin{array}{l}\text { Unintentional or incidental (fugitive) (during production, } \\
\text { handling, use and disposal of MNP products) }\end{array}$ \\
\hline Atmospheric life time & Low & $\begin{array}{l}\text { Unknown (expected to be relatively larger than ANPs but } \\
\text { depending on type) }\end{array}$ \\
\hline $\begin{array}{l}\text { Preferred measurement metric } \\
\text { for regulation }\end{array}$ & Number & Unknown (number, mass or surface area) \\
\hline $\begin{array}{l}\text { General shape of particle } \\
\text { number/size distributions }\end{array}$ & $\begin{array}{l}\text { Bi-modal (changing continuously } \\
\text { due to the effect of transformation } \\
\text { processes) }\end{array}$ & Unimodal or bimodal depending on material \\
\hline Exposure route & Oral, dermal, inhalation & Oral, dermal, inhalation or ingestion \\
\hline Adverse health effects & Fairly well known & Largely unknown \\
\hline Surface area/volume & High & High \\
\hline $\begin{array}{l}\text { Uniformity in shape, size and } \\
\text { functionality }\end{array}$ & Low & High \\
\hline $\begin{array}{l}\text { Instruments generally used for } \\
\text { measuring ambient number } \\
\text { distributions }\end{array}$ & $\begin{array}{l}\text { SMPS, DMS500, DMS50, ELPI, } \\
\text { CPC, CNC, APS, FMPS, UFP, } \\
\text { LAS }\end{array}$ & SMPS, CPC \\
\hline
\end{tabular}

Note that these are generic properties of MNPs which can differ depending on the material

SMPS scanning mobility particle sizer, DMS differential mobility spectrometer, ELPI electrical low pressure impactor, $C P C$ condensation particle counter, $C N C$ condensation nucleus counter, $A P S$ aerodynamic particle sizer, $F M P S$ fast mobility particle sizer, $U F P$ ultrafine particle monitor, $L A S$ laser aerosol spectrometer

concerns about their impact. These observations support the view that the answer to the question posed should be in the affirmative.

Potential concentrations of ambient MNPs can be assessed through life cycle analysis of MNP-integrated products (Kapustka et al. 2009). Such assessments are rare in the nanotechnology sector and, where made, are mostly based on properties of the bulk material which have substantially different characteristics than the actual nanomaterials used in the products (Helland et al. 2007). The sparsity of life cycle analysis is probably due to the time required for, and the complexity of a full analysis. Choi et al. (2009) argue that a thorough hazard assessment of all existing MNP-integrated products in the USA may take several decades (i.e. about 30-50 years), an ever increasing target as new nanomaterials emerge.
Muller and Nowack (2008) derived some information on $\mathrm{MNP}$ (silver, $\mathrm{TiO}_{2}$ and CNT) mass concentrations (ranging between about $10^{-2}$ and $10^{-3} \mu \mathrm{gm}^{-3}$ ) by differentiating from the ANPs in the environment of Switzerland. Overall, though there is little or no knowledge of current background number concentrations and distributions of air-dispersed MNPs. Thus, it is a challenging task to estimate their current and future concentrations in the environment. To date, no reports of MNP number concentrations in ambient environments or increased number concentrations in production or work environments have been published (Fujitani et al. 2008; Möhlmann et al. 2009). This could well reflect the limited capabilities of existing instrumentation (see section on "instruments"). Future advances in instrumentation coupled with more frequent use of MNP- 
integrated products may lead to MNPs emerging as an important class of ANPs in both the ambient environment and work places.

What is the appropriate measurement metric?

In common with other ANPs, the best metrics to represent the toxicity and environmental risks associated with MNPs include their generic properties (e.g. particle size distribution, shape, number concentrations and surface area) and more specific properties (e.g. agglomeration state, crystal structure, chemical composition, surface chemistry, surface charge or porosity) (Oberdörster et al. 2005; Stone et al. 2009). Recent studies indicate that some easily measurable or generic properties of MNPs (i.e. particle number, surface area or mass concentrations) can be related to their health effects (Duffin et al. 2007). Mass concentrations are unimportant, as MNPs (particles with one dimension in the 1$100 \mathrm{~nm}$ size range; BSI 2005) contribute little to mass, but far more to particle number and surface area concentrations. However, somewhat confusingly, mass concentrations are generally specified as the dose metric in toxicological studies. Basic questions regarding the association of MNP characteristics with adverse health effects and the precise biological mechanism by which they affect human health are still unanswered. Although it is unwise to use any single metric, the use of particle number concentrations could simplify the determination of the appropriate metric, at least for ambient measurements. This is especially the case considering that use of number concentrations of ANPs is widely accepted (e.g. Euro-5 and Euro-6 vehicle emission standards; EU 2008).

Can the same instruments be applied to measure air-dispersed MNPs and ANPs?

MNPs may differ from ANPs in numerous aspects, such as aspect ratio, size distribution, chemical composition, homogeneity or heterogeneity (Xia et al. 2009). For example, a few types of MNPs (e.g. nanotubes, nanowires, nanobelts and nanopillars, etc.) have very high aspect ratios relative to ANPs (Iijima 1991). As summarised in Table 1, techniques for the measurement of ANPs include the scanning mobility particle sizer (SMPS), differential mobility spectrometer (DMS500), electrical low pressure impactor and condensation particle counter (Kumar et al. 2008a, c). These are generally also used for measuring MNPs (Kuhlbusch et al. 2004; Fujitani et al. 2008). The SMPS is generally used as a benchmark instrument for measurement of number and size distributions of both ANPs and MNPs. It detects particles based on their electrical mobility equivalent diameter (i.e. the diameter of a spherical particle that has the same electrical mobility as the irregular particle in question). Use of such a benchmark instrument or others working on same principle, implies questions about the appropriate electrical charging of MNPs, which have different physical and chemical characteristics than ANPs (Xia et al. 2009). For example, a HSE (2006) report observed that under certain circumstances the SMPS has the potential to alter the structure of the sampled particles due to the bi-polar charging process it employs in the size classification of the aerosol. Moreover, measurements with instruments operating on different working principles (e.g. SMPS and ELPI) could have different responses even when the same type of particle is treated (Asbach et al. 2009). Satterstrom et al. (2009) raised similar issues and reported that MNPs are not easily detected and monitored at workplaces and it is unclear whether existing instruments are adequate. As there are no standard instrumentation guidelines for measurement of ANPs and MNPs, the instruments discussed above will continue to be used until their capabilities are improved or new instruments developed.

The related question might be 'is it currently possible to differentiate MNPs from ambient ANPs?' Clearly, from the foregoing, current instrumentation does not have the capability to apportion MNPs from other ANPs. However, recent studies suggest indirect ways to make the distinction through models (Muller and Nowack 2008) or life cycle analysis (Kapustka et al. 2009). Another method would be to sample MNP production or work place environments using real-time instruments (e.g. the CPC), as releases will lead to substantial short-term increases in concentration (Ono-Ogasawara et al. 2009). Another common approach is through chemical characterisation (electron and atomic force microscopy, X-ray scattering and diffraction) of particles by observing their morphology and elemental composition (Ju-Nam and Lead 2008). These methods can only be carried 
out in the laboratory or at an off-site location and do not provide real-time determination of the bulk quantity of particles that are essential for air quality control. It is clear that there are substantial uncertainties regarding the best way to measure MNPs, uncertainties that must be addressed before appropriate regulation can be developed.

Are the dispersion characteristics of MNPs and ANPs similar?

Understanding of the dispersion characteristics of airborne MNPs is essential to assess human health and environmental risks. The persistence and dispersion of MNPs are likely to be comparable to those of other ANPs, but with type-specific degrees of transformation and loss processes.

The atmospheric life time of ANPs depends on their susceptibility to a variety of transformation (i.e. coagulation, condensation, nucleation and evaporation, etc.) and loss (i.e. dry or wet deposition, etc.) processes, and the number of particles present in the air controls the collision processes (Hinds 1999). ANPs concentrations generally show bi-modal distributions covering a wide range of polydisperse particles over a size range from nanometres to tens of micron in diameter (Kumar et al. 2008b). ANPs undergo a number of transformation processes because of their complex chemical composition and morphology, processes that constantly change the particle size distribution and reduce their life time in the ambient environment (Kulmala et al. 2004; Kumar et al. 2009b). Understanding of their dispersion in various environments (e.g. vehicle wakes, street canyons, city or global scales) is fairly well known (Kumar 2008).

The transformation, loss and dispersion processes that affect ANPs are also applicable to the dispersion of MNPs, and it can be argued that the behaviour of MNPs is relatively better known in air than in other media (e.g. water, soils and sediments; Muller and Nowak 2008). The precise nature of transformation and loss processes will, of course, depend on the specific physicochemical properties of MNPs (especially those of large aspect ratios such as CNTs) and background concentrations. Atmospheric dispersion characteristics of MNPs depend on the degree of sedimentation, agglomeration or disintegration (Casals et al. 2008), matters of less importance in the case of ANPs because of their relatively lower surface reactivity and higher volatility. Sedimentation is likely to be more important for MNPs (especially where concentrations might be large, such as near production units or workplaces) as they have strong tendencies to form colloids. Their relatively large surface area and surface energy promote agglomeration and rapid growth beyond the $100 \mathrm{~nm}$ cut-off point for nanoparticles when concentrations are sufficiently high (Maynard 2007). This changes their atmospheric life time in a manner that depends critically on the local number concentrations, as illustrated in the following simple example (Hinds 1999).

In a busy road-side atmospheric environment


particle takes about 14 days to grow ten times larger but, in stark contrast, if a leak occurred in a nanomaterials manufacturing unit (concentration,

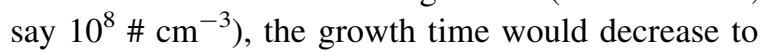
$3 \mathrm{~h}$, reducing to $1 \mathrm{~s}$ at extremely high concentrations

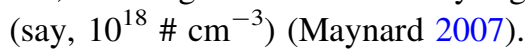

It follows from the above discussion that MNPs (irrespective of their types) and ANPs can be treated in the same manner in outdoor particle dispersion models (Holmes and Morawska 2006; Kumar et al. 2009c) with appropriate assumptions and modifications. In MNP-prone indoor environments (e.g. production units or workplaces) where measurements can be more effective than modelling, specific laws for MNPs should be included in workplace directives.

Is exposure to MNPs a concern?

Maynard (2007) discussed the question "will people be really exposed to individual and agglomerated MNPs?', and concluded that the answer was 'yes'. The literature also confirms the exposure of the general public to MNPs, despite their production in controlled environments (Tsuji et al. 2006; Maynard and Kuempel 2005). Maynard (2004) reports that 'up to 2 million US workers are currently exposed to ultra-fine materials and an estimated one million more workers could be exposed through work in nanotechnology-based industries in the next decade'. $\mathrm{He}$ also reported that exposure levels of MNP mass concentrations were typically orders of magnitude higher than environmental exposures. 
Exposure is usually through oral, dermal, inhalation or ingestion routes, depending on the patterns of MNPs use (Oberdörster et al. 2005). An example of inhalation could be fullerene particles, which are normally found in the air in the aggregated, or agglomerated, state. Once inhaled, they may deposit deep in the lung and deagglomerate in the alveolar lining fluid (Fujitani et al. 2008). Recent studies indicate that MNPs (inorganic or carbon nanostructures) do not cause acute toxic effects at realistic doses, but prolonged exposure could lead to human health hazards (Casals et al. 2008).

It is widely held that an identification and understanding of the hazard posed by MNP-integrated products, together with identification of the likelihood of human exposure and the inhaled dose at different stages of a product's life, are key research requirements that will enable realistic life cycle analyses to be undertaken.

\section{Summary and concluding remarks}

Inhalation of the MNPs from ambient air is a dominant pathway for population exposure. Thus far, regulatory standards worldwide for controlling ANPs in the ambient or indoor environments are extremely limited. Our comparison of manufactured and airborne nanoparticles shows modest differences in their characteristics and behaviour, insufficient enough to influence the potential regulatory framework for ANPs. However, the expected widespread use of MNP products and the current emphasis on developing innovative methods for detecting MNPs from the environment or workplace through exploiting their specific properties (i.e. magnetic, optical, electrical, electrochemical or physical) will eventually bring precise information on air-dispersed MNPs. Furthermore, a separate regulatory framework for MNP production and/or work environments, where the likelihood of significant concentrations and exposure is greater, might be required upon consideration of policy and governing issues (Franco et al. 2007; Satterstrom et al. 2009). The discussion also highlighted a number of only partially addressed aspects of the study of airborne MNPs. Thorough investigation of these could yield better understanding of the differences between manufactured nano and other airborne particles, thus filling the data gap, and providing a valuable input to the decision makers finalising research strategies and regulatory issues for both indoor and ambient environments.

Acknowledgements PK thanks members of Surrey University's Nanoscience Interest Group for valuable discussions on this topic during the meetings. He also thanks the EPSRC (grant EP/H026290/1) for supporting his research on atmospheric nanoparticles.

\section{References}

Anastasio C, Martin ST (2001) Atmospheric nanoparticles. In: Banfield JF, Navrotsky A (eds) Nanoparticles and the environment, vol 44. Mineralogical Society of America, Washington, pp 293-349

Andujar P, Lanone S, Brochard P, Boczkowski J (2009) Respiratory effects of manufactured nanoparticles. Rev Mal Respir 26:625-637

Asbach C, Kaminski H, Fissan H, Monz C, Dahmann D, Mülhopt S, Paur HR, Kiesling HJ, Herrmann F, Voetz M, Kuhlbusch TAJ (2009) Comparison of four mobility particle sizers with different time resolution for stationary exposure measurements. J Nanoparticle Res 11:1593-1609

Brouwer D (2009) Exposure to manufactured nanoparticles in different workplaces. Toxicol. doi:10.1016/j.tox.2009. 1011.1017

BSI (2005) Vocabulary-nanoparticles. PAS 71

Bystrzejewska-Piotrowska G, Golimowski J, Urban PL (2009) Nanoparticles: their potential toxicity, waste and environmental management. Waste Manag 29:2587-2595

Casals E, Vázquez-Campos S, Bastús NG, Puntes V (2008) Distribution and potential toxicity of engineered inorganic nanoparticles and carbon nanostructures in biological systems. Trends Anal Chem 27:672-683

Choi J-Y, Ramachandran G, Kandlikar M (2009) The impact of toxicity testing costs on nanomaterial regulation. Environ Sci Technol 43:3030-3034

Cientifica (2009) Nanotechnology takes a deep breath and prepares to save the earth! Global Nanotechnology funding in 2009 Cientifica Ltd 2009; pp 1-7. Download from: http://cientifica.eu/attachments/054_Nanotechnology\%020 Takes\%020a\%020Deep\%020Breath.pdf. Accessed April 2009

Dawson NG (2008) Sweating the small stuff: environmental risk and nanotechnology. Bioscience 58:690

Duffin R, Mills NL, Donaldson K (2007) Nanoparticles-A thoracic toxicology perspective. Yonsei Med J 48:561562

Evelyn A, Mannick S, Sermon PA (2002) Unusual carbonbased nanofibres and chains among diesel-emitted particles. Nano Lett 3:63-64

Franco A, Hansen SF, Olsen SI, Butti L (2007) Limits and prospects of the "incremental approach" and the European legislation on the management of risks related to nanomaterials. Regul Toxicol Pharm 48:171-183

Fujitani Y, Kobayashi T, Arashidani K, Kunugita N, Suemura $\mathrm{K}$ (2008) Measurement of the physical properties of 
aerosols in a fullerene factory for inhalation exposure assessment. J Occup Environ Hyg 5:380-389

Helland A, Wick P, Koehler A, Schmid K, Som C (2007) Reviewing the environmental and human health knowledge base of carbon nanotubes. Environ Health Perspect 115:1125-1131

Hinds WC (1999) Aerosol technology: properties behaviour and measurement of airborne particles. Wiley, London, $p$ 483

Holmes NS, Morawska L (2006) A review of dispersion modelling and its application to the dispersion of particles: an overview of different dispersion models available. Atmos Environ 40:5902-5928

HSE (2006) The assessment of different metrics of the concentration of nano (ultrafine) particles in existing and new industries. Health and Safety Executive 2006, 80 pp

Iijima S (1991) Helical microtubules of graphitic carbon. Nature 354:56-58

Ju-Nam Y, Lead JR (2008) Manufactured nanoparticles: an overview of their chemistry, interactions and potential environmental implications. Sci Total Environ 400:396414

Kapustka L, Chan-Remillard S, Goudey S (2009) Developing an ecological risk framework to assess environmental safety of nanoscale products. In: Linkov I, Steevens J (eds) Nanomaterials: risks and benefits. Springer Science+ Business Media, pp 149-159

Köhler AR, Som C, Helland A, Gottschalk F (2008) Studying the potential release of carbon nanotubes throughout the application life cycle. J Clean Prod 16:927-937

Kuhlbusch TA, Neumann S, Fissan H (2004) Number size distribution, mass concentration, and particle composition of PM1, PM2.5, and PM10 in bag filling areas of carbon black production. J Occup Environ Hyg 1:660671

Kulmala M, Vehkamaki H, Petaja T, Dal Maso M, Lauri A, Kerminen V-M, Birmili W, McMurry PH (2004) Formation and growth rates of ultrafine particles: a review of observations. J Aerosol Sci 35:143-176

Kumar P (2008) Measurements and modelling of the dispersion of nanoparticles in the urban environment. PhD Thesis, University of Cambridge, $226 \mathrm{pp}$

Kumar P, Fennell P, Britter R (2008a) Measurements of particles in the 5-1000 $\mathrm{nm}$ range close to road level in an urban street canyon. Sci Total Environ 390:437-447

Kumar P, Fennell P, Britter R (2008b) Effect of wind direction and speed on the dispersion of nucleation and accumulation mode particles in an urban street canyon. Sci Total Environ 402:82-94

Kumar P, Fennell P, Langley D, Britter R (2008c) Pseudosimultaneous measurements for the vertical variation of coarse, fine and ultra fine particles in an urban street canyon. Atmos Environ 42:4304-4319

Kumar P, Fennell P, Symonds J, Britter R (2008d) Treatment of losses of ultrafine aerosol particles in long cylindrical sampling tubes during ambient measurements. Atmos Environ 42:8819-8826

Kumar P, Robins A, Britter R (2009a) Fast response measurements for the dispersion of nanoparticles in a vehicle wake and in a street canyon. Atmos Environ 43:61106118
Kumar P, Fennell P, Hayhurst A, Britter RE (2009b) Street versus rooftop level concentrations of fine particles in a Cambridge street canyon. Bound Layer Meteorol 131:3-18

Kumar P, Garmory A, Ketzel M, Berkowicz R, Britter R (2009c) Comparative study of measured and modelled number concentrations of nanoparticles in an urban street canyon. Atmos Environ 43:949-958

Maynard AD (2004) Small times. Researchers discuss safety guidelines for handling nanomaterials. Download from: http://www.electroiq.com/index/display/nanotech-articledisplay/269453/articles/small-times/bio/2004/05/researchersdiscuss-safety-guidelines-for-handling-nanomaterials.html

Maynard AD (2006) Nanotechnology: a research strategy for addressing risk. Woodrow Wilson International Centre for Scholars, Washington, DC, pp 1-45

Maynard AD (2007) Is engineered nanomaterial exposure a myth? Safe nano website (www.safenano.org), pp 1-5

Maynard AD, Kuempel ED (2005) Airborne nanostructured particles and occupational health. J Nanoparticle Res 7:587-614

Möhlmann C, Welter J, Klenke M, Sander J (2009) Workplace exposure at nanomaterial production processes. In: Nanosafe international conference on safe production and use of nanomaterials, vol 170. pp 1-5

Muller NC, Nowack B (2008) Exposure modeling of engineered nanoparticles in the environment. Environ Sci Technol 42:4447-4453

Nowack B (2009) The behaviour and effects of nanoparticles in the environment. Environ Pollut 157:1063-1064

Oberdörster G, Maynard A, Donaldson K, Vincent Castranova V, Fitzpatrick J, Ausman K, Carter J, Karn B, Kreyling W, Lai D, Olin S, Monteiro-Riviere N, Warheit D, Yang H (2005) Principles for characterizing the potential human health effects from exposure to nanomaterials: elements of a screening strategy. Part Fibre Toxicol 2(8):1-35

Ono-Ogasawara M, Serita F, Takaya M (2009) Distinguishing nanomaterial particles from background airborne particulate matter for quantitative exposure assessment. J Nanoparticle Res 11:1651-1659

Pey J, Querol X, Alastuey A, Rodríguez S, Putaud JP, Van Dingenen R (2009) Source apportionment of urban fine and ultra fine particle number concentration in a Western Mediterranean city. Atmos Environ 43:4407-4415

Roco M (2005) International perspective on government nanotechnology funding in 2005. J Nanoparticle Res 7:707-712

Roco MC, Bainbridge, WS (2001) Societal implications of nanoscience and nanotechnology. Springer (formerly Kluwer) Publications. Nanoscale, Sceince, Engineering and Technology (NSET) Workshop Report, 280 pp. Download from: http://www.wtec.org/loyola/nano/NSET.Societal. Implications/nanosi.pdf

Satterstrom FK, Arcuri ASA, Davis TA, Gulledge W, Hansen SF, Haraza MAS, Kapustka L, Karkan D, Linkov I, Melkonyan M, Monica J, Owen R, Palma-Oliveira JM, Srdjevic B (2009) Considerations for implementation of manufactured nanomaterial policy and governance. In: Nanomaterials: risks and benefits. pp 329-350

Stone V, Nowack B, Baun A, van den Brink N, von der Kammer F, Dusinska M, Handy R, Hankin S, Hassellöv M, Joner E, Fernandes TF (2009) Nanomaterials for 
environmental studies: classification, reference material issues, and strategies for physico-chemical characterisation. Sci Total Environ. doi:10.1016/j.scitotenv.2009. 1010.1035

The Royal Society (2004) Nanoscience and nanotechnologies: opportunities and uncertainities. The Royal Society \& The Royal Academy of Engineering, London, $127 \mathrm{pp}$. Download from: http://www.nanotec.org.uk/finalReport. htm
Tsuji JS, Maynard AD, Howard PC, James JT, Lam C-w, Warheit DB, Santamariak AB (2006) Research strategies for safety evaluation of nanomaterials, Part IV: risk assessment of nanoparticles. Toxicol Sci 89:42-50

Xia T, Li N, Nel AE (2009) Potential health impact of nanoparticles. Ann Review Pub Health 30:137-150 